\title{
Information Technology and Libraries at 50: The 1990s in Review
}

Steven K.

Bowers

I played some computers games - stored on data cassette tapes - in the 1980s. That was entertaining, but I never imagined the greater hold that computers would have on the world by the mid-1990s. I can remember getting my first email account in 1993, and looking at information on rudimentary web pages in 1996. I remember my work shifting from an electric typewriter to a bulky personal computer with dial-up Internet access. Eventually, this new computing technology became a prevalent part of my everyday life. This shift to a computer-driven reality had a major effect on libraries too. I was amazed by the end of the 1990s to be doing research on a university library catalog system connected with other institutions of higher education throughout the region, wondering at the expanded access to, and reach of, information. In my mind, due to computers and the Internet, libraries were really connected at that time more than they had ever been. As I prepared this review of what we were writing about in ITAL in the 1990s, I had some fond memories of the advent of personal computers in my daily life and in the libraries I had access to. As we take a look back, I think it is interesting to see what we were doing then and how it is connected to what we are still working on today.

Along with the eventual disruption that the Internet was to libraries, computers and online access also had the effect of greatly changing how libraries constructed our core research tools, especially the catalog. Prior to the 1990s libraries had begun automation projects to move their catalogs to computer-based terminals, creating connections and access that were not previously possible with a card catalog. If we are still complaining about the design and function of the Online Public Access Catalog (OPAC) today, in the early 1990s we were discussing what their design and function should be, in a positive and optimistic way. In some ways it seems hard to recall the discussions of how to format data and display it to users. In other ways it seems like we are still having the same discussions, but our work has become more complex as we continue to restructure library data to become more open and accessible. While we were contemplating the design of online library catalogs, libraries were also discussing the implementation of networking and other information technology infrastructures. Nevins and Learn examined the changes in hardware, software, and telecommunications at the time and predicted a more affordable cost model with distributed personal computers connected through networks, and enhancing library automation cooperation. ${ }^{1}$ They expanded the discussion to include consideration of copyright and intellectual property, security, authorization, and a need for information literacy in the form of user navigation, all key to what we are doing today.

Beyond catalogs, there was the real adoption of the Internet itself. By the early 1990s there was growing enthusiasm for accessing and exploring the Internet. ${ }^{2}$ This created a need for libraries to learn about the Internet and instruct others on how to use it. As late as 1997, however, even search engines were still being introduced and defined, and using the Internet or searching the World Wide Web was still a new concept that was not fully understood by many people. At their

Steven K. Bowers (sbowers@wayne.edu) is Executive Director, Detroit Area Library Network (DALNET). 
basis, search engines were simply defined as indexing and abstracting databases for the web. ${ }^{3}$ It is interesting that library catalogs were developed separately from the development of search engines and we are still trying to get our metadata out of our closed systems and open to the rest of the web.

In 1991, Kibirige examined the potential impact of this new connectivity on library automation. He posited that "One of the most significant change agents that will pervade all other trends is the establishment and regular use of high-speed, fiber optic communication highways."4 His article in ITAL provides a prescient overview of much of what has played out in technology, not just in libraries. He noted the need for disconnected devices to become tools to access full-text information remotely. ${ }^{5}$ Perhaps most important, he noted the need for librarians to become experts in non-library technology, to keep pace with developments outside of the profession. This admonition is still important to keep in mind today. At the time, however, libraries were working on the basics of converting records from online bibliographic utility systems running on mainframes to a more useful format for access on a personal computer, let alone thinking about transforming library metadata into linked data that can be accessed by rest of the Internet. So we keep moving forward.

Later in the decade, libraries began to think about the library catalog as a "one stop shop" for information. In 1997, Caswell wrote about new work to integrate local content, digital materials, and electronic resources, all into one search interface. Initially the discussion was more technical in nature, but Caswell provided an early concept for providing a single access point to all of the content that the library has, print and electronic, which was a step forward from just listing the books in the catalog. ${ }^{6}$ At the time we were still far away from our current concept of a full discovery system with access to millions of electronic resources that may well surpass the print collections of a library.

Eventually more discussion developed around the importance of user experience and usability for the design of catalogs and websites. Catalogs were examined in parallel with the structure of library metadata, and both were seen as important to the retrievability of library materials. Human-machine interaction was starting to be examined on the staff side of systems, and this would eventually become part of examining the public interface usability as well. Outlining an agenda for redesigning online catalogs, Buckland summarized this new technological development work for libraries by noting that "Sooner or later we need to rethink and redesign what is done so that it is not a mechanization of paper but fully exploits the capabilities of the new technology." 7 More exciting, by the end of the 1990s we were seeing usability studies for specific populations and those with accessibility difficulties. Systems were in wide enough use that libraries began to examine their usefulness to more audiences.

Beyond our systems, the technology of our actual collections was changing. New network connectivity combined with new hardware led to new formats for library resources, specifically digital and electronic resources. In 1992, Geraci and Langschied summarized these changes, stating that "what is new for the 1990s is the complication of a greater variety of electronic format, software, hardware, and network decisions to consider."8 They also expanded the conversation to include data in all forms, and data sets of various kinds, well beyond traditional library materials. This is an important evolution as libraries worked to shift their operations, identities, and curatorial practices. Geraci and Langschied defined data by type, including social data, scientific 
data, and humanities data. They called most importantly for libraries to include access to this varied data to continue the role of libraries providing access to information, as they cautioned that information seekers were already beginning to bypass libraries and look for such information from other sources. Libraries were beginning to lose ground as the gatekeepers of information and needed to shift to providing online access and open data themselves.

The early 1990s were an exciting time for preservation, as discussion was moving from converting materials to microforms to digitization. In 1990, Lesk compared the two formats and had hope for a promising digital future. ${ }^{9}$ Thank goodness he was on target for sharing resources and creating economical digital copies, even if he did not completely predict the eventual shift to reliance on electronic resources that many research libraries have now made. Lesk also noted the importance of text recognition, optical character recognition (OCR), and text formatting in ASCII. Others focused on digital file formats and the planning and execution of creating digital collections. Digitization practices were developing and the need to formalize practice was becoming evident. The same year, Lynn outlined the relationship between digital resources and their original media, highlighting preservation, capture, storage, access, distribution. ${ }^{10}$ By the late 1990 s there were more targeted discussions about the benefits of digitizing resources to provide not only remote access, but access to archival materials specifically. In 1996, Alden provided a good primer on everything to consider when doing digitization projects, within budget constraints. ${ }^{11}$

By the mid-1990s, Karen Hunter was excited to extol the promises of the dissemination of information electronically, calling the High Performance Computing and High Speed Networking Applications Act of 1993 "[a] formidable vision and goal. Real-time access to everything and a laser printer in every house. The 1990s equivalent to a chicken in every pot." ${ }^{2}$ Hunter's article is a good overview of where libraries were at working with electronic publications and online access in the early 1990s. Halcyon Enssle's piece on moving reserves to online access opened with a great summary of where much of library access was headed: "The virtual library, libraries without walls, the invisible user ... these are some of the terms getting used to describe the library of the future...."13 Eventually, by the end of the decade we even learned to start tracking how our new online libraries were being used, applying our knowledge of print resource usage to our new online collections.

In 1995, Laverna Saunders had already developed a new definition of what a library was, and how the transformation of libraries from physical warehouses to providing access to online content would affect workflows in libraries. As defined by Saunders, "the virtual library is a metaphor for the networked library, consisting of electronic and digital resources, both local and remote." 14 Not a bad definition more than 20 years later. Saunders asked pertinent questions such as which resources would be best in print vs. online, what print materials should be retained, and which resources and collections libraries should digitize themselves. The broader view provided was that these changes would affect not just collections but the entire operation of libraries. There would still be work to do in libraries, but changes in the work were necessary to address shifting technology and the composition of collections. By the end of the decade there was new work to assess use of electronic resources, extended virtual reference services, and information literacy extending to technology instruction.

In 1998, Kopp wrote about the promising future of library collaborations. Consortia were well established in prior decades and they were seeing a resurgence. Kopp noted that just as consortia 
had been built around support for new shared utilities in the 1970s and 1980s, in the 1990s they were finding a new purpose in the new networking of the Internet and possibilities of greater connectivity and collaborations in the online environment. ${ }^{15}$ Beyond cataloging and automation technology, it is interesting to note that even in the new online environment that was forming in the 1990s, many consortia formed at the time to share print resources. This may have been conversely related to libraries shifting from complete print collections to online holdings that many may have felt were more ephemeral, or maybe money was spent on new technological infrastructures and less on library materials. Resource sharing of print materials is still an important part of libraries working together to provide access to information, and since the time that Kopp wrote about consortia and growing networked collaborations, there has also been a growing development of sharing electronic resources. A large part of the work of many consortia today revolves around purchasing of electronic resources, but in the late 1990s libraries were just beginning to get into purchasing commercial electronic resources. ${ }^{16}$

There were lots of ITAL articles in the 1990s looking at the future of libraries and technology, and some specific articles dedicated to prognostication. In 1991, looking into the future, Kenneth E. Dowlin shared a vision for public libraries in 2001. He predicted that libraries would still exist but it is noteworthy that at the time the future existence of libraries was questioned by many. Dowlin did predict change for libraries, including the confluence of new media formats, computing, and yes, still books. He stated what time has now confirmed: "The public wants them all."17 He had lots of other interesting ideas as well; his article is worth a second look. Another fun take on the future was a special section on Science Fiction from 1994 considering Future Possibilities in Information Technology and Access. In one piece, David Brin noted, "Nobody predicted that the home computer would displace the mega-machine and go on to replace the rifle over the fireplace as freedom's great emancipator, liberating common citizens as no other technology has since the invention of the plow." ${ }^{18}$ An interesting observation, even if the computer has now been replaced by phones in our pockets or other fantastic wearable technologies.

By the end of the 1990s, libraries had been greatly transformed by technology. Many libraries had automated, workflows continued to adjust in all areas of library work, and most libraries had at least partially incorporated elements of using the Internet along with providing computer access to library users. Some libraries were already moving through the change from print to electronic library resources. Specific web applications and websites were also being developed and used for and by libraries. These eventually have matured into smarter systems that can provide better access to our collections and smarter assessment of our resource usage, for both print and electronic materials. As a whole, the 1990s are an exciting time to review when looking at the intersection of information technology and libraries. As information dissemination moved to an online environment, within and outside of the profession, the future existence of libraries began to be questioned. As we now know, libraries still play an important role in providing access to information.

\section{NOTES}

${ }^{1}$ Kate Nevins and Larry L. Learn, "Linked Systems: Issues and Opportunities (Or Confronting a Brave New World)," Information Technology and Libraries 10, no. 2 (1991): 115. 
${ }^{2}$ Constance L. Foster, Cynthia Etkin, and Elaine E. Moore, "The Net Results: Enthusiasm for Exploring the Internet," Information Technology and Libraries 12, no. 4 (1993): 433-6.

${ }^{3}$ Scott Nicholson, "Indexing and Abstracting on the World Wide Web: An Examination of Six Web Databases," Information Technology and Libraries 16, no. 2 (1997): 73-81.

${ }^{4}$ Harry M. Kibirige, "Information Communication Highways in the 1990s: An Analysis of their Potential Impact on Library Automation," Information Technology and Libraries 10, no. 3 (1991): 172.

${ }^{5}$ Kibirige, “Information Communication Highways in the 1990s,” 175.

${ }^{6}$ Jerry V. Caswell, "Building an Integrated User Interface to Electronic Resources," Information Technology and Libraries 16, no. 2 (1997): 63-72.

${ }^{7}$ Michael K. Buckland, “Agenda for Online Catalog Designers," Information Technology and Libraries 11, no. 2 (1992): 162.

${ }^{8}$ Diane Geraci and Linda Langschied, "Mainstreaming Data: Challenges to Libraries," Information Technology and Libraries 11, no. 1 (1992): 10.

${ }^{9}$ Michael Lesk, "Image Formats for Preservation and Access," Information Technology and Libraries 9, no. 4 (1990): 300-308.

${ }^{10}$ M. Stuart Lynn, “Digital Imagery, Preservation, and Access--Preservation and Access Technology: The Relationship between Digital and Other Media Conversion Processes: A Structured Glossary of Technical Terms," Information Technology and Libraries 9, no. 4 (1990): 309-336.

${ }^{11}$ Susan Alden, “Digital Imaging on a Shoestring: A Primer for Librarians," Information Technology and Libraries 15, no. 4 (1996): 247-50.

12 Karen A. Hunter, "Issues and Experiments in Electronic Publishing and Dissemination," Information Technology and Libraries 13, no. 2 (1994): 127.

${ }^{13}$ Halcyon R. Enssle, "Reserve on-Line: Bringing Reserve into the Electronic Age," Information Technology and Libraries 13, no. 3 (1994): 197.

${ }^{14}$ Laverna M. Saunders, "Transforming Acquisitions to Support Virtual Libraries," Information Technology and Libraries 14, no. 1 (1995): 41.

15 James J. Kopp, “Library Consortia and Information Technology: The Past, the Present, the Promise," Information Technology and Libraries 17, no. 1 (1998): 7-12.

${ }^{16}$ International Coalition of Library Consortia, "Guidelines for Statistical Measures of Usage of Web-Based Indexed, Abstracted, and Full Text Resources," Information Technology and Libraries 17, no. 4 (1998): 219-21; Charles T. Townley and Leigh Murray, "Use-Based Criteria 
for Selecting and Retaining Electronic Information: A Case Study," Information Technology and Libraries 18, no. 1 (1999): 32-9.

${ }^{17}$ Kenneth E. Dowlin, “Public Libraries in 2001," Information Technology and Libraries 10, no. 4 (1991): 317.

18 David Brin, "The Good and the Bad: Outlines of Tomorrow," Information Technology and Libraries 13, no. 1 (1994): 54. 